\title{
Candida sorbosivorans sp. nov., a new member of the genus Candida Berkhout
}

National Collection of Yeast Cultures, Food Safety Science Division, Institute of Food Research, Norwich NR4 7UA, UK

\author{
Stephen A. James, Christopher J. Bond and Ian N. Roberts \\ Author for correspondence: Stephen A. James. Tel: +44 1603 255000. Fax: +44 1603458414. \\ e-mail: Steve.James@bbsrc.ac.uk
}

Keywords: Candida sorbosivorans sp. nov., new yeast species, 26S rDNA

\section{INTRODUCTION}

Using the identification methods of van der Walt \& Yarrow (1984) and Yarrow (1998), a yeast, strain NCYC $2938^{\mathrm{T}}$, was found to be physiologically similar, but not identical, to Candida geochares and its close relative Candida magnoliae (Meyer et al., 1998; Kurtzman \& Robnett, 1998). Strain NCYC $2938^{\mathrm{T}}$ was isolated from contaminated industrial material, involved in a cascade continuous process for oxidizing sorbitol (D-glucitol) to L-sorbose (used in producing vitamin C). The sequence of the $26 \mathrm{~S}$ rDNA D1/D2 domain of NCYC $2938^{\mathrm{T}}$ was determined and compared with those of C. geochares and C. magnoliae to establish whether it was an atypical strain of either yeast, or a different species of the genus Candida (see Kurtzman \& Robnett, 1998). According to Kurtzman and his colleagues, conspecific yeast strains typically display fewer than $1 \%$ nucleotide substitutions in this region of the $26 \mathrm{~S}$ rDNA, whereas strains belonging to separate species generally (though not always) display larger numbers of substitutions (Kurtzman, 1998; Kurtzman \& Robnett, 1991, 1998; Peterson \& Kurtzman, 1991). Our decision to describe NCYC $2938^{\mathrm{T}}$ as a new species of the anamorphic genus Candida, namely Candida sorbosivorans sp. nov., is based on its physiological characteristics and the $26 \mathrm{~S}$ rDNA sequence data.

The EMBL accession number for the 26S rDNA sequence of the D1/D2 region of NCYC $2938^{\top}$ is AJ277846.

\section{METHODS}

Yeast strains and phenotypic characterization. The yeast strains examined in this study are listed in Table 1 and are available from the National Collection of Yeast Cultures (NCYC), Norwich, UK, and the Centraalbureau voor Schimmelcultures (CBS), Delft, The Netherlands. All strains were grown on YM agar $(0 \cdot 3 \%$ yeast extract, $0.3 \%$ malt extract, $0.5 \%$ peptone, $1 \%$ glucose, $2 \%$ agar; $\mathrm{pH} 5 \cdot 5)$ at $24{ }^{\circ} \mathrm{C}$ and maintained on YM agar slopes at $4{ }^{\circ} \mathrm{C}$. The novel isolate was assigned the strain number NCYC $2938^{\mathrm{T}}$ and was characterized phenotypically using the standard yeast-identification tests as described by van der Walt \& Yarrow (1984) and Yarrow (1998).

Growth-rate comparisons for different carbon sources. Commercial D-glucitol (Sigma) was recrystallized twice from the pyridine-glucitol complex, which was thermally destroyed, and the pyridine was removed under reduced pressure (Strain, 1934, 1937). The D-glucitol was then recrystallized twice from methanol. All incubations were carried out at $25^{\circ} \mathrm{C}$ in $10 \mathrm{ml}$ medium in $100 \mathrm{ml}$ conical flasks. The flasks were shaken reciprocally at approximately 75 cycles min $^{-1}$ and $10 \mathrm{~cm}$ travel. Each yeast strain was grown overnight in $1 \%(\mathrm{w} / \mathrm{v})$ Difco yeast extract with $50 \mathrm{mM}$ substrate (Dglucose, D-glucitol or L-sorbose) in order to acclimatize (i.e. induce or derepress) the yeast, particularly to D-glucitol and L-sorbose. Each growth was then filtered through a membrane filter and resuspended in Difco yeast nitrogen base with $50 \mathrm{mM}$ substrate corresponding to that on which it had been grown. The cell suspensions were adjusted initially to an $\mathrm{OD}_{640} \approx 0 \cdot 3$. Each growth was measured at least four times at $640 \mathrm{~nm}$ and calibrated in terms of dry weight (Barnett, 1968). Doubling times were calculated from the linear relationship between the logarithm of dry weight and time, during exponential growth. 
Table 1. Yeast strains examined in this study

For full species descriptions of C. geochares and C. magnoliae, refer to Meyer et al. (1998). Abbreviations: CBS, Centraalbureau voor Schimmelcultures, Delft, The Netherlands; NCYC, National Collection of Yeast Cultures, Norwich, UK.

\begin{tabular}{|lll|}
\hline Species & \multicolumn{1}{c|}{ Strain } & \multicolumn{1}{c|}{ Source of isolate } \\
\hline Candida geochares & CBS 6870 & Grassland soil, South Africa \\
Candida magnoliae & NCYC 742 & Unknown \\
& NCYC 765 & Unknown \\
& NCYC 2620 & Flower of Magnolia sp. \\
Candida sorbosivorans & NCYC 2938 & Sorbitol-to-sorbose continuous fermentation cascade \\
\hline
\end{tabular}

26S rDNA sequencing and sequence analysis. The variable D1 and D2 domains of the 26S rDNA were PCR-amplified directly from individual yeast colonies by using the protocol detailed by James et al. (1994) and the conserved fungal oligonucleotide primers NL1 and NL4 described by O'Donnell (1993). The amplified 26S rDNA PCR products were purified using a QIAGEN QIAquick PCR purification kit according to the manufacturer's instructions.

Direct sequencing of the purified 26S rDNA PCR products was performed using a Taq DyeDeoxy terminator cycle sequencing kit (PE Biosystems) and an Omnigene thermal cycler (Hybaid) according to the manufacturers' recommendations. The 26S rDNA sequences were determined using NL1 and NL4 as sequencing primers. Purified sequencing reaction mixtures were electrophoresed with a PE Biosystems model 373A automated DNA sequencer.

The determined 26S rDNA D1/D2 sequence of strain NCYC $2938^{\mathrm{T}}$ was compared with sequences held in both the EMBL and GenBank sequence databases. A sequence alignment of the 26S rDNA sequences for NCYC $2938^{\mathrm{T}}$ and its closest relatives was created by using the multiplesequence alignment program PILEUP (Feng \& Doolittle, 1987) contained within the GCG software package (Genetics Computer Group, 1991) version 8.1. Phylogenetic analyses were performed using PHYLIP (Felsenstein, 1993) version 3.572. A distance matrix was generated using the DNADIST program with the Jukes-Cantor distance measure and a rooted phylogenetic tree was constructed by using the neighbour-joining method (Saitou \& Nei, 1987) and the NEIGHBOR program. The stability of individual branches of the tree was assessed by the bootstrap method (Felsenstein, $1985)$ with the programs SEQBOOT, DNADIST, NEIGHBOR and CONSENSE. A total of 456 nucleotides was determined from the $26 \mathrm{~S}$ rDNA D1/D2 region of NCYC $2938^{\mathrm{T}}$.

\section{RESULTS AND DISCUSSION}

\section{Phenotypic characterization}

The morphological and physiological characteristics of NCYC $2938^{\mathrm{T}}$ were determined by using standard methods, as described by Yarrow (1998), and are shown in Table 2. Use of the yeast-identification program of Barnett (1996) revealed that strain NCYC $2938^{\mathrm{T}}$ possessed physiological characteristics similar, though not identical, to those of $C$. geochares and its close relative C. magnoliae (see Kurtzman \& Robnett, 1998). NCYC $2938^{\mathrm{T}}$ differed from C. geochares by its ability to assimilate both raffinose (albeit slowly) and potassium nitrate and from $C$. magnoliae by its inability to assimilate either D-ribose or ethanol. As well as these assimilatory differences, NCYC $2938^{\mathrm{T}}$ was found to grow at $40^{\circ} \mathrm{C}$. In contrast, strains of both $C$. geochares and $C$. magnoliae can grow only at temperatures up to $37^{\circ} \mathrm{C}$ (and only weakly in the case of C. geochares) (Meyer et al., 1998).

To assess the significance of the D-glucitol (sorbitol) growth characteristic of NCYC $2938^{\mathrm{T}}$, additional tests were performed. As this isolate had originally been recovered as a contaminant from a sorbitol-to-sorbose fermentation cascade (Table 1), the growth rates (measured as doubling times) for NCYC $2938^{\mathrm{T}}$ and the type strains of $C$. geochares (CBS $6870^{\mathrm{T}}$ ) and $C$. magnoliae (NCYC $2620^{\mathrm{T}}$ ) grown on D-glucose, Dglucitol (sorbitol) or L-sorbose were measured. On Dglucose, the growth rates of C. geochares CBS $6870^{\mathrm{T}}$, C. magnoliae NCYC $2620^{\mathrm{T}}$ and strain NCYC $2938^{\mathrm{T}}$ were measured as $5 \cdot 8 \pm 0 \cdot 3,4 \cdot 1 \pm 0 \cdot 5$ and $4 \cdot 8 \pm 0 \cdot 3 \mathrm{~h}$, respectively. For D-glucitol (sorbitol), the rate of growth was determined only for NCYC $2938^{\mathrm{T}}$ $(5 \cdot 6 \pm 0 \cdot 2 \mathrm{~h})$, as the other two yeasts were found to flocculate in the presence of this sugar. For L-sorbose, the growth rates of all three yeasts were extremely slow (doubling times in excess of $6.0 \mathrm{~h}$ ) and no differences between the three yeasts were evident. These results indicated further clear physiological differences, consistent with the evolution of a new species adapted to growth in D-glucitol (sorbitol) and exhibiting an intermediate growth rate on D-glucose.

\section{S rDNA sequence analysis}

The 26S rDNA D1/D2 variable domain of NCYC $2938^{\mathrm{T}}$ was amplified in vitro by using the PCR and the nucleotide sequence was determined directly. This sequence was used initially to search the EMBL and GenBank sequence databases in an attempt to establish the identity of this yeast isolate. Results of the search revealed that the NCYC $2938^{\mathrm{T}} \mathrm{D} 1 / \mathrm{D} 2$ sequence was most similar to those of $C$. geochares and its close relative C. magnoliae (Kurtzman \& Robnett, 1998). However, the D1/D2 sequence of NCYC $2938^{\mathrm{T}}$ 
Table 2. Physiological characteristics of $C$. sorbosivorans sp. nov.

Characters are scored as: +, positive; L, delayed (latent); s, slow; w, weak; -, negative.

\begin{tabular}{|c|c|c|c|}
\hline Character & Score & Character & Score \\
\hline Fermentation of carbohydrates & & Assimilation of carbon compounds (cont.) & \\
\hline D-Glucose & + & Galactitol & - \\
\hline Sucrose & + & D-Mannitol & + \\
\hline Maltose & - & D-Glucitol & + \\
\hline D-Galactose & - & Methyl $\alpha$-D-glucoside & - \\
\hline Lactose & - & Salicin & $\mathrm{L}$ \\
\hline Cellobiose & - & DL-Lactate & - \\
\hline$\alpha, \alpha$-Trehalose & - & Succinate & $\mathrm{L}$ \\
\hline Melibiose & - & Citrate & + \\
\hline Melezitose & - & Inositol & - \\
\hline Raffinose & - & D-Glucono-1,5-lactone & + \\
\hline Methyl $\alpha$-D-glucoside & - & D-Glucosamine & - \\
\hline Inulin & - & Methanol & - \\
\hline Soluble starch & - & Ethanol & - \\
\hline Assimilation of carbon compounds & & Xylitol & + \\
\hline D-Glucose & + & Assimilation of nitrogen compounds & \\
\hline D-Galactose & $\mathrm{s}$ & Nitrate & + \\
\hline L-Sorbose & + & Ethylamine & + \\
\hline Sucrose & + & Cadaverine & + \\
\hline Maltose & - & L-Lysine & + \\
\hline Cellobiose & $\mathrm{L}$ & Additional growth characteristics & \\
\hline$\alpha, \alpha$-Trehalose & - & $10 \% \mathrm{NaCl} / 5 \%$ glucose & + \\
\hline Lactose & - & $15 \% \mathrm{NaCl} / 5 \%$ glucose & + \\
\hline Melibiose & - & $20 \% \mathrm{NaCl} / 5 \%$ glucose & + \\
\hline Raffinose & $\mathrm{L}$ & $50 \%$ D-Glucose & + \\
\hline Melezitose & w & $60 \%$ D-Glucose & + \\
\hline Inulin & - & $0.01 \%$ Cycloheximide & $\mathrm{s}$ \\
\hline Starch & - & $0 \cdot 1 \%$ Cycloheximide & w \\
\hline D-Xylose & - & Urease activity & - \\
\hline L-Arabinose & - & $1 \%$ Acetic acid & - \\
\hline D-Arabinose & - & Lipolytic activity & - \\
\hline D-Ribose & - & Acid production & - \\
\hline Glycerol & + & Arbutin hydrolysis & s \\
\hline L-Rhamnose & - & Starch formation & - \\
\hline Erythritol & $\mathrm{s}$ & Growth at $37^{\circ} \mathrm{C}$ & + \\
\hline Ribitol & + & Growth at $40{ }^{\circ} \mathrm{C}$ & + \\
\hline
\end{tabular}

differed by five base substitutions from that of the $C$. geochares type strain (CBS $6870^{\mathrm{T}}$ ) and by six base substitutions from that of the C. magnoliae type strain $\left(\mathrm{NCYC} 2620^{\mathrm{T}}\right)$. This suggested that isolate NCYC $2938^{\mathrm{T}}$ belonged to a separate species, as conspecific strains typically differ by no more than three base substitutions (i.e. $<1.0 \%$ sequence divergence) in this region of the 26S rDNA (Kurtzman, 1998; Kurtzman \& Blanz, 1998; Kurtzman \& Robnett, 1998). Indeed, when the D1/D2 sequences of two other strains (NCYC 742 and NCYC 765) of C. magnoliae were determined, both were found to be identical to that of the type strain, NCYC $2620^{\mathrm{T}}$. In comparison, the D1/D2 sequences of the type strains of $C$. geochares $\left(\mathrm{CBS} 6870^{\mathrm{T}}\right.$ ) and C. magnoliae (NCYC $2620^{\mathrm{T}}$ ) differ from one another by a total of nine base substitutions.
The 26S rDNA D1/D2 sequences of NCYC $2938^{\mathrm{T}}, C$. geochares, C. magnoliae and a number of other related Candida species (see Fig. 10 of Kurtzman \& Robnett, 1998) were aligned and the derived distances were used to infer phylogenetic relationships. Fig. 1 shows a rooted tree (with Candida blankii as the outgroup) constructed by using the neighbour-joining method and depicts the phylogenetic placement of NCYC $2938^{\mathrm{T}}$ in relation to $C$. geochares, $C$. magnoliae and some other Candida species. Although NCYC $2938^{\mathrm{T}}$ is phylogenetically closely related to both $C$. geochares and $C$. magnoliae, with the three yeasts forming a distinct species group (bootstrap value $94 \%$ ), it would appear that NCYC $2938^{\mathrm{T}}$ belongs to a hitherto unknown species of Candida. Therefore, on the basis of both the physiological and 26S rDNA sequence 


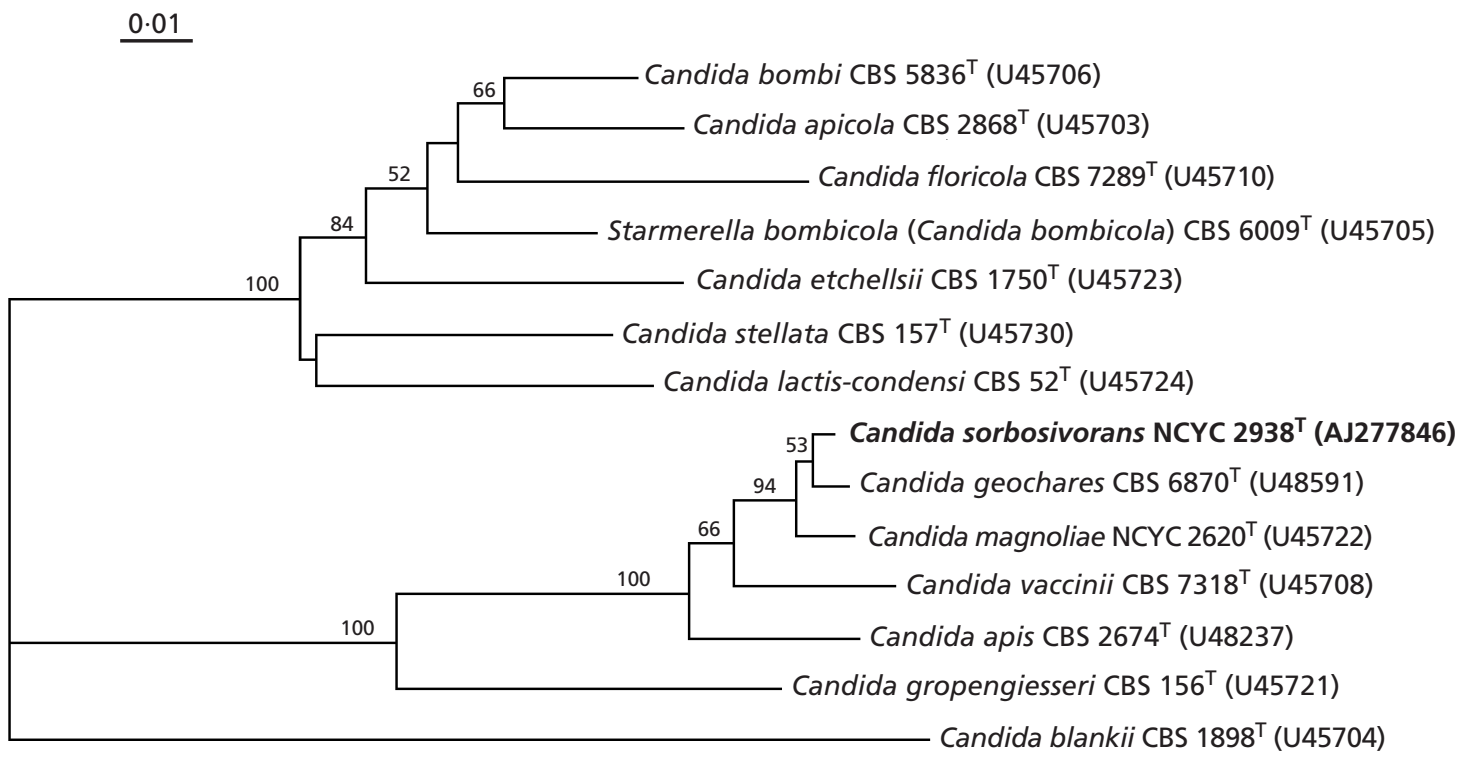

Fig. 1. Dendrogram showing the phylogenetic relationship between Candida sorbosivorans NCYC $2938^{\top}$ and the type strains of other related Candida species, based on 26S rDNA D1/D2 gene sequences. The tree was constructed by using the neighbour-joining method (Saitou \& Nei, 1987). Bootstrap values, expressed as percentages of 200 replications, are given at branch nodes (only values $>50 \%$ are shown). Bar, 1 estimated base substitution per 100 nucleotide positions. The EMBL/GenBank accession numbers for the 26S rDNA D1/D2 gene sequences used in the analysis are shown in parentheses.

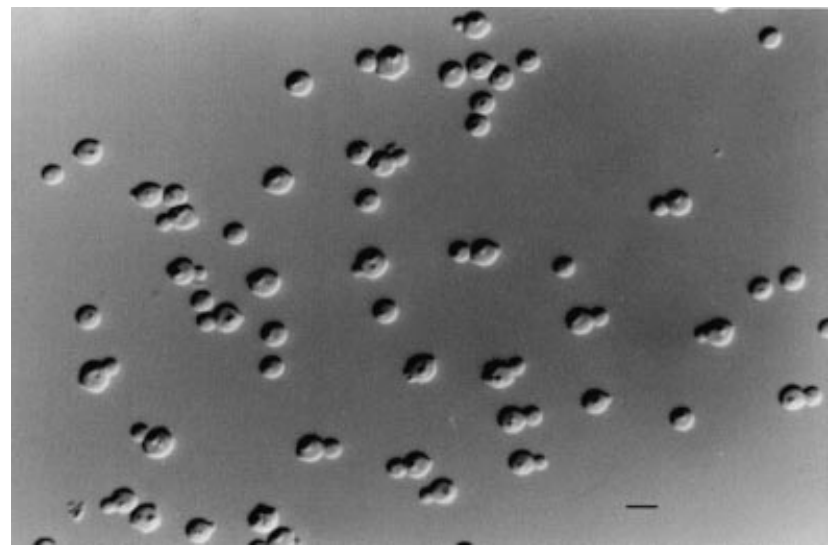

Fig. 2. Photomicrograph of strain NCYC $2938^{\top}$ grown in YNBG medium ( $25 \mathrm{mM}$ D-glucose) for $1 \mathrm{~d}$ at $25^{\circ} \mathrm{C}$. Bar, $5 \mu \mathrm{m}$.

data, we describe a new species, C. sorbosivorans $\mathrm{sp}$. nov., to accommodate strain NCYC $2938^{\mathrm{T}}$.

\section{Latin diagnosis of Candida sorbosivorans James, Bond et Roberts sp. nov.}

Cultura in agaro morphologico (Difco) post 48 horas ad $24{ }^{\circ} \mathrm{C}$ : cellulae ovoideae $(2 \cdot 0-4 \cdot 0 \times 3 \cdot 0-5 \cdot 0 \mu \mathrm{m})$, singulae, binae, adhaerentes, per gemmationem multipolarem reproducentes. Ascomata nulla post 20 dies $24{ }^{\circ} \mathrm{C}$ seu in agaro farina maydis confecto se PDA seu medio Gorodkowae. Glucosum et sucrosum fermentantur at non maltosum, galactosum, lactosum, cellobiosum, trehalosum, melibiosum, melezitosum, raffinosum, methyl $\alpha$-D-glucosidum, inulinum, nec amylum. Glucosum, galactosum, L-sorbosum, sucrosum, cellobiosum, raffinosum, melezitosum, erythritolum, ribitolum, Dmannitolum, D-glucitolum, salicinum, acidum succinicum, acidum citricum, glucono-D-lactonum, glycerinum, xylitolum, nitrus kalicus, ethylaminum, lysinum, et cadaverinum assimilantur at non maltosum, trehalosum, lactosum, melibiosum, inulinum, amylum, D-xylosum, Larabinosum, D-arabinosum, D-ribosum, L-rhamnosum, galactitolum, methyl $\alpha$-D-glucosidum, acidum lacticum, inositolum, D-glucosaminum, metanolum nec alcohol aethylicum. Crescit in medio cum $60 \%$ glucoso et in medio $0 \cdot 1 \%$ cycloheximido addito. Non crescit in medio $1 \%$ acido acetico addito. Typus depositus in collectionis 'National Collection of Yeast Cultures', Norwich, Britannia (NCYC 2938 ${ }^{\mathrm{T}}$ ).

\section{Description of Candida sorbosivorans James, Bond et Roberts sp. nov.}

Candida sorbosivorans (sor.bos.i.vor'ans. N.L. sorbosum sorbose; L. part. adj. vorans devouring; N.L. gen. n. sorbosivorans devouring sorbose, referring to the ability of the new species to assimilate sorbose).

On morphology agar, after $48 \mathrm{~h}$ at $24^{\circ} \mathrm{C}$, the cells are spherical to ovoid $(2 \cdot 0-4 \cdot 0 \times 3 \cdot 0-5 \cdot 0 \mu \mathrm{m})$ and occur singly, in pairs or in groups (Fig. 2). Budding is multilateral. No ascosporulation was observed after cultures had been incubated for 3 weeks at $24^{\circ} \mathrm{C}$ on either corn-meal agar, potato-dextrose agar or Gorodkowa agar. For a summary of the physiological 
and other growth characteristics of strain NCYC $2938^{\mathrm{T}}$, see Table 2. Cultures of the type strain have been deposited with the National Collection of Yeast Cultures, Norwich, UK (NCYC 2938 ${ }^{\mathrm{T}}$ ), and with the Centraalbureau voor Schimmelcultures, Delft, The Netherlands (CBS 8768 ${ }^{\mathrm{T}}$ ).

\section{ACKNOWLEDGEMENTS}

We thank Dr James Barnett, School of Biological Sciences, University of East Anglia, for his assistance with the physiological characterization of NCYC $2938^{\mathrm{T}}$, for kindly providing the photomicrograph of this yeast and for his critical and invaluable review of the manuscript and Dr Walter Gams at the Centraalbureau voor Schimmelcultures, Delft, for his kind assistance with the Latin nomenclature of this organism.

\section{REFERENCES}

Barnett, J. A. (1968). The catabolism of acyclic polyols by yeasts. J Gen Microbiol 52, 131-159.

Barnett, J. A. (1996). Yeast Identification PC program: version 4. ISBN 0951314882.

Felsenstein, J. (1985). Confidence limits on phylogenies: an approach using the bootstrap. Evolution 39, 783-791.

Felsenstein, J. (1993). PHYLIP: phylogenetic inference package, version 3.5. University of Washington, Seattle, WA, USA.

Feng, D. F. \& Doolittle, R. F. (1987). Progressive sequence alignment as a prerequisite to correct phylogenetic trees. $J \mathrm{Mol}$ Evol 25, 351-360.

Genetics Computer Group, (1991). Program Manual for the GCG Package, Version 7. Madison, WI: Genetics Computer Group.

James, S. A., Collins, M. D. \& Roberts, I. N. (1994). Genetic interrelationship among species of the genus Zygosaccharomyces as revealed by small-subunit rRNA gene sequences. Yeast 10, 871-881.

Kurtzman, C. P. (1998). Yeast systematics - from phenotype to genotype. Food Technol Biotechnol 36, 261-265.
Kurtzman, C. P. \& Blanz, P. A. (1998). Ribosomal RNA/DNA sequence comparisons for assessing phylogenetic relationships. In The Yeasts, a Taxonomic Study, 4th edn, pp. 69-74. Edited by C. P. Kurtzman \& J. W. Fell. Amsterda: Elsevier.

Kurtzman, C. P. \& Robnett, C. J. (1991). Phylogenetic relationships among species of Saccharomyces, Schizosaccharomyces, Debaryomyces and Schwanniomyces determined from partial ribosomal RNA sequences. Yeast 7, 61-72.

Kurtzman, C. P. \& Robnett, C. J. (1998). Identification and phylogeny of ascomycetous yeasts from analysis of nuclear large subunit (26S) ribosomal DNA partial sequences. Antonie Leeuwenhoek 73, 331-371.

Meyer, S. A., Payne, R. W. \& Yarrow, D. (1998). Candida Berkhout. In The Yeasts, a Taxonomic Study, 4th edn, pp. 454-573. Edited by C. P. Kurtzman \& J. W. Fell. Amsterdam: Elsevier.

O'Donnell, K. (1993). Fusarium and its near relatives. In The Fungal Holomorph: Mitotic, Meiotic and Pleomorphic Speciation in Fungal Systematics, pp. 225-233. Edited by D. R. Reynolds \& J. W. Taylor. Wallingford: CAB International.

Peterson, S. W. \& Kurtzman, C. P. (1991). Ribosomal RNA sequence divergence among sibling species of yeasts. Syst Appl Microbiol 14, 124-129.

Saitou, N. \& Nei, M. (1987). The neighbor-joining method: a new method for reconstructing phylogenetic trees. Mol Biol Evol 4, 406-425.

Strain, H. H. (1934). $d$-Sorbitol: a new source, method of isolation, properties and derivatives. $\mathrm{J}$ Am Chem Soc 56, 1756-1759.

Strain, H. H. (1937). Sources of $d$-Sorbitol. J Am Chem Soc 59, 2264-2266.

van der Walt, J. P. \& Yarrow, D. (1984). Methods for isolation, maintenance, classification of yeasts. In The Yeasts, a Taxonomic Study, 3rd edn, pp. 45-104. Edited by N. J. W. Kregervan Rij. Amsterdam: Elsevier.

Yarrow, D. (1998). Methods for the isolation, maintenance and identification of yeasts. In The Yeasts, a Taxonomic Study, 4th edn, pp. 77-100. Edited by C. P. Kurtzman \& J. W. Fell. Amsterdam: Elsevier. 